\title{
Toxicologia Forense - Teoria e Prática
}

\author{
M. Passagli ${ }^{a}$, P.A. Marinho ${ }^{b, *}$ \\ ${ }^{a}$ Secretaria de Estado de Defesa Social, Belo Horizonte $(M G)$, Brasil. \\ ${ }^{b}$ Seção Técnica de Física e Química Legal do Instituto de Criminalística de Minas Gerais, Belo Horizonte (MG), Brasil. \\ *Endereço de e-mail para correspondência: pabloalvesmarinho@yahoo.com.br. Tel.: +55-31-33301773
}

Recebido em 12/09/2012; Revisado em 06/09/2013; Aceito em 10/09/2013

\section{RESENHA}

Passados seis anos da $1^{\text {a }}$ edição nos preparamos para fazer uma $4^{\mathrm{a}}$ edição melhor que as anteriores. Neste trabalho continuamos contando com a maioria dos nossos colaboradores iniciais os quais se empenharam ao máximo em busca da divulgação do estado da arte da toxicologia forense. Com o objetivo de ampliar a abrangência da obra, o capítulo de Análises Toxicológicas em Matrizes Biológicas merece destaque nesta publicação. Este capítulo é todo dedicado aos ensaios realizados nas amostras colhidas in vivo e, principalmente, post mortem oriundas de casos suspeitos de intoxicações exógenas acidentais ou propositais. Ainda neste capítulo, são apresentados todos os cuidados com a cadeia de custódia, incluindo a documentação, rastreabilidade e cuidados das amostras para envio ao laboratório, a fim de manter sua integridade e confidencialidade. Discutimos também os diferentes métodos de preparo de amostras empregados em matrizes biológicas complexas. As técnicas analíticas mais amplamente utilizadas na identificação e quantificação de agentes tóxicos são apresentadas no novo capítulo de Cromatografia e Espectrometria de Massas, sendo abordadas de uma forma muito prática.

Mantendo sempre o espírito inovador da obra apresentamos um capítulo, abordando uma nova área da toxicologia, denominada de Entomotoxicologia. Este capítulo tem como objetivo discutir as análises de substâncias (drogas, metais, praguicidas, fármacos) em artrópodes que se alimentaram de carcaças humanas, a fim de constatar a utilização destes toxicantes pela vítima ou avaliar como eles podem interferir no ciclo de vida dos insetos. A aplicação desta ciência, com seus procedimentos e metodologias, permite ampliar a obtenção de provas materiais na investigação criminal, em especial quando o uso dos métodos tradicionais está esgotado ou não se tem os resultados esperados para solução de um caso.

Seguindo as políticas públicas da SENASP, que firmou convênios de cooperação junto ao INMETRO e ABNT, tendo sido propostas mudanças fundamentais como a acreditação de laboratórios forenses e a certificação dos profissionais da área, aprimoramos o capítulo de Validação de Métodos Químicos dada sua importância neste contexto. Este capítulo enfatiza de forma clara o quanto é importante para formação da prova material qualificada o conceito de controle de qualidade do serviço forense prestado à sociedade brasileira.

Nesta nova edição, como nas anteriores, propomos expor de forma didática os conceitos, procedimentos e metodologias aplicadas e discutimos a melhor forma de prestação deste importante serviço forense para sociedade. Assim, acreditamos que esta $4^{\mathrm{a}}$ edição poderá continuar contribuindo na formação e capacitação de novos profissionais das ciências forenses e dos operadores do Direito.

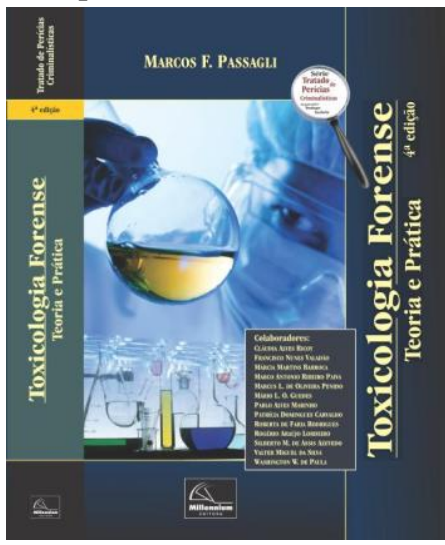

Toxicologia Forense / Marcos F. Passagli. - 4. Ed. - Campinas: Editora Millennium, 2013.

Número de páginas: 496

Formato: $16 \mathrm{~cm}$ por $23 \mathrm{~cm}$

ISBN 978-85-7625-297-9 